\title{
Полицейско-правовая теория конца XIX - начала XX века о личности - субъекте публично-правовых отношений в полицейском государстве
}

\author{
${ }^{1)}$ Нижник Н.С., ${ }^{2)}$ Дергилева С.Ю. \\ ${ }^{1)}$ Санкт-Петербургский университет МВД России \\ 198206, Россия, г. Санк-Петербург, ул. Летчика Пилютова, д. 1 \\ E-mail: n.nishnik@bk.ru \\ ${ }^{2)}$ Белгородский юридический институт МВД России имени И.Д. Путилина \\ 308024, Россия, г. Белгород, ул. Горького, д. 71 \\ E-mail: sdergileva@mvd.ru
}

\begin{abstract}
Аннотация. Констатируя наличие различных социальных статусов подданных сословно организованной Российской империи, ученые-полицеисты особое внимание уделяли проблемам, касающимся соотношения общественных, государственных и личных интересов, а также моделям обеспечения прав личности в имперской России конца XIX - начала XX в. Целью исследования является определение подходов российских полицеистов к характеристике личности как объекта управленческой деятельности в полицейском государстве и субъекта частноправовых и публичноправовых отношений, а также к определению оптимальной модели механизма защиты прав личности - субъекта публично-правовых отношений в российском государстве, поскольку, несмотря на интерес современных исследователей к ретроспективному анализу полицейскоправовой теории, эти вопросы до настоящего времени в историко-правовой науке осмысления не получили. Понимание проблем законодательного закрепления прав и свобод личности и их реализации, осуществленное полицейско-правовой теорией в конце XIX - начале XX в., может быть использовано для совершенствования механизма защиты прав личности - субъекта публично-правовых отношений в современной России.
\end{abstract}

Ключевые слова: полицейское государство, полиция, полицейское право, административное право, публично-правовые отношения, полицеисты.

Для цитирования: Нижник Н.С., Дергилева С.Ю. 2020. Полицейско-правовая теория конца XIX начала XX века о личности - субъекте публично-правовых отношений в полицейском государстве. NOMOTHETIKA: Философия. Социология. Право. 45 (4): 750-760. DOI 10.18413/2712-746X2020-45-4-750-760

\section{Police and legal theory of the late XIX - early XX century about a person as a subject of public law relations in a police state}

\author{
${ }^{1)}$ Nadezhda S. Nizhnik, ${ }^{2}$ Svetlana Y. Dergileva \\ ${ }^{1)} 1$ Lyotchik Pilyutov street, Saint-Petersburg, Russia, 198206 \\ E-mail: n.nishnik@bk.ru \\ ${ }^{2)}$ Belgorod Law Institute of the Ministry of Internal Affairs of Russia named after I.D. Putilin \\ 71 Gor'kogo street, Belgorod, Russia, 308024 \\ E-mail: sdergileva@mvd.ru
}

\begin{abstract}
Stating the existence of various social statuses of subjects of the class-organized Russian Empire, political scientists paid special attention to problems related to the correlation of public, state and
\end{abstract}


personal interests, as well as models for ensuring individual rights in Imperial Russia in the late XIXearly XX centuries. The aim of the study is to determine the approaches of Russian police officers to the characterization of the individual as an object of management activity in the police state and the subject of private and public law relations, as well as to determine the optimal model of the mechanism for protecting the rights of the individual as a subject of public law relations in the Russian state, since, despite the interest of modern researchers in the retrospective analysis of police law theory, these issues have not yet been understood in historical and legal science. The understanding of the problems of legislative consolidation of individual rights and freedoms and their implementation, implemented by the police-legal theory in the late XIX - early XX centuries, can be used to improve the mechanism for protecting the rights of the individual - the subject of public law relations in modern Russia.

Key words: police state, police, police law, administrative law, public law relations, policeists.

For citation: Nizhnik N.S., Dergileva S.Y. 2020. Police and legal theory of the late XIX - early XX century about a person as a subject of public law relations in a police state. NOMOTHETIKA: Philosophy. Sociology. Law series. 45 (4): 750-760 (in Russian). DOI 10.18413/2712-746X-2020-45-4750-760

\section{Введение}

В западноевропейской научной и общественной мысли XVIII - начала XX века значимое место занимали вопросы, касающиеся организации и функционирования монархического государства, важными элементами механизма которого являлись полиция и полицейская деятельность. В начале XVIII в. во Франции был опубликован четырехтомный трактат Н. Деламара о полиции [Delamare, 1719-1738], которым было положено начало становлению науки о полиции, полицейской деятельности и полицейского государства. Идеи, высказанные Н. Деламаром, получили дальнейшее развитие в работах немецких ученых Х. фон Вольфа, И.Г.Г. фон Юсти и И.Ф. фон Зонненфельса [Wolff, 1740-1748; Justi, 1759;1765-1769], которые предприняли попытку определить предмет, цели, задачи и систему полицейского права.

В России наука полицейского права начала формироваться в конце XVII в. Благодаря вниманию к проблемам полицейского права видных российских юристов И.Е. Андреевского [1874-1876], И.Т. Тарасова [1888], Э.Н. Берендтса [1898], В.М. Гессена [1902, 1903, 1908], В.В. Ивановского [1908], В.Ф. Дерюжинского [1917], А.И. Елистратова [1917] уже в XIX в. полицейское право в России оформилось как самостоятельная национальная юридическая наука, были определены ее предмет, метод, система, понятийнокатегориальный аппарат. Полицейско-правовая теория - полицеистика - в России конца XIX - начала XX в. отличалась тем, что ученые ставили и решали широкий круг разнообразных вопросов. В частности, полицеисты пришли к выводам о том, что обеспечение прав общества на самостоятельность, саморазвитие, самосохранение и самоуправление является главным предназначением государства, которое реализуется с помощью законодательства, правосудия, полиции и армии; что основой полицейской деятельности правительства является не столько принуждение, сколько создание государством социальноправовых гарантий материального и нравственного развития народа; что принудительная деятельность государства проявляется в борьбе с опасностями, стоящими на пути к благосостоянию населения, а также о том, что полиция безопасности и полиция благосостояния - это не учреждения, а сферы деятельности административных органов.

Полицеисты отмечали, что политико-правовая реальность, сложившаяся в Западной Европе и России в Новое время, в научной литературе получила название полицейского государства. Чертами полицейского государства являлись полицейская деятельность, проникающая во все сферы общественной жизни; всесторонняя подробная регламентация народной жизни; опека органов государственной власти над нуждами и интере- 
сами своих подданных; подавление личной и общественной инициативы, самостоятельности; отрицание гражданских прав и свобод подданных; игнорирование прав личности по отношению к органам государственной власти: обыватель в полицейском государстве рассматривался как обезличенный объект для правительственных мероприятий [Нижник, Дергилева, 2017].

Констатируя наличие различных социальных статусов подданных сословно организованной Российской империи, ученые-полицеисты в своей научной, общественной и государственной деятельности особое внимание уделяли проблемам, касающимся соотношения общественных, государственных и личных интересов, а также моделям обеспечения прав личности в имперской России конца XIX - начала XX в. Для решения практических вопросов усовершенствования управления государством и определения эффективных способов регулирования общественных отношений полицеисты подвергли анализу вопросы, касающиеся характеристики личности как объекта управленческой деятельности в полицейском государстве, как субъекта частноправовых и публично-правовых отношений, а также касающиеся механизмов защиты прав личности - субъекта публичноправовых отношений.

В современной историко-правовой науке были сделаны выводы о том, что концептуальную основу полицейско-правовой теории в XVIII-XIX вв. составляла философия эвдемонизма и утверждения о том, что цель государства - обеспечение своим подданным счастья [Нижник и др., 2014], что полицеистика в числе важнейших проблем рассматривала комплекс вопросов, связанных с законодательным закреплением и обеспечением прав и свобод личности [Егоров, 2020; Козинникова, 2020; Нижник, Никифорова, 2019]. Представления о субъектах правоотношений, о государстве и личности как субъектах взаимодействия и субъектах правоотношений на разных этапах полицейско-правовой теории были разными [Нижник, Дергилева, 2014; Нижник, Никифорова, 2019; Nizhnik N., 2019; Пирожок, 2020; Морозова, Нижник, 2020; Козинникова, 2020], но в конце XIX - начале $\mathrm{XX}$ в. представления о доминирующих социальных регуляторах претерпевают сущностные трансформации, изменяются теоретические подходы к конструированию полицейского и правового государства, иными становятся оценки права как регулятора общественных отношений [Нижник, 2018]. Несмотря на интерес современных исследователей к ретроспективному анализу полицейско-правовой теории [Нижник, 2019; Дергилева, 2019; Туманова, 2019], взгляды российских полицеистов на личность как объект управленческой деятельности в полицейском государстве и субъект частноправовых и публичноправовых отношений до настоящего времени в историко-правовой науке осмысления не получили, представления полицеистов об оптимальной модели механизма защиты прав личности - субъекта публично-правовых отношений в российском государстве оценки не имеют. Решению данных задач посвящено настоящее исследование.

\section{Личность как объект управленческой деятельности в полицейском государстве}

Отношения личности и полицейского государства рассматривались как имеющие публично-правовой характер. Однако фактически личность оценивалась как принадлежность государства. Государство становилось «на место народа, рассматривало себя как самоцель и превращало народ в подчиненное средство. Государство, признавая себя не только самоцелью, но и единственно возможной целью в общественном сознании людей, стремилось превратить народные массы в послушное орудие для осуществления своих задач» [Кистяковский, 1916].

Полицейское государство подчиняло всю деятельность людей исключительно своим интересам, превращая народ в средство для достижения своих целей, подчеркивал Б. А. Кистяковский. Полицейское государство личность игнорировало и отрицало за ней 
какие-либо права в той области, куда оно распространяло или желало распространить свое властвование [Кистяковский, 1916].

Никаких прав по отношению к государственной власти у подданных не имелось, констатировал А.М. Гессен, так как правам подданных должны соответствовать обязанности государства [1908а], а у правительства, не ограниченного в своих действиях законом, по отношению к подданным обязанностей нет. Полицейское государство, делал вывод B.M. Гессен, знает отношения подданства и не знает отношений гражданства [Гессен, 1908б], которые предполагают, что индивид является субъектом прав, а не объектом государственной власти [Гессен В.М., 1918].

Проблемы регулирования субъективных публичных прав личности являлись центральными в научной, общественной и государственной деятельности А.И. Елистратова, который в конце XIX в. обосновал необходимость изменения предмета полицейского права и формирования «учения о правоотношениях, которые возникают между людьми в области государственного управления», - административного права, предметом которого должна явиться система правоотношений, складывающаяся на основе административной деятельности [Елистратов, 1910; 1910-1911; 1911; 1914; 1915;1917]. Елистратов пришел к выводу, что переход от системы отношений между правящими и управляемыми, не урегулированных правом, к системе отношений, урегулированных правом, выступает детерминантой превращения полицейского законодательства в административное [Нижник, Дергилева, 2017], чем внес важный вклад в переход в российской юриспруденции от науки «полицейское право» к науке «административное право».

\section{Полицейско-правовая теория о личности как субъекте частноправовых и публично-правовых отношений}

Правоотношения, складывающиеся между людьми в области управления в правовом государстве, предполагают конструирование модели прав и обязанностей граждан на одинаковых основаниях с обязанностями и правами должностных лиц и государственных органов. Ученые-полицеисты выявляли основания для упорядочения правоотношений, складывающихся между государством и гражданином. Французские административисты обратили внимание на сходство между административным и гражданским правом, определенное тем, что корни административно-правовых и гражданско-правовых институтов находились в публичном праве. Публичное вещное право они рассматривали в широком смысле как находящееся между правом гражданина на пользование определенными благами и институтом государственной службы, а в качестве основы системы административного права выделяли субъективные права граждан - право личной свободы, политические права, имущественные права.

Среди прав граждан в публично-правовой сфере центральное место занимают личные права, которые обеспечивают человеку сферу свободы от полицейского и иного государственного вмешательства и в своей совокупности образуют право личной свободы. Право личной свободы имеет общие черты с гражданскими личными правами. Права личности в ее взаимоотношениях с другими частными лицами определяются в сфере гражданско-правовых отношений, а права личности в контексте ее отношений с государственными учреждениями - в сфере административно-правовых отношений. В основе цивилистических личных прав лежит частный интерес, в основе административно-правовых отношений - интересы публичного характера. Закрепление за личностью права личной свободы заставляет администрацию воздерживаться от совершения определенных действий, в отношении эту свободу нарушающих. Это означает, что право личной свободы является притязанием не на положительную деятельность должностного лица, а на его бездействие в определенных направлениях, то есть имеет негативный характер. Но обеспечение права личной свободы не обходится и без положительной деятельности со стороны администра- 
тивных учреждений: администрация выдает лицу различные разрешения, удостоверения, требующиеся ему, например, при передвижении, регистрирует общественные организации и союзы и т. д. Принимая во внимание эти факты, А.И. Елистратов сделал вывод о том, что реализация права личной свободы будет осложняться правопритязаниями позитивного характера - требованиями положительного обеспечения свободного пользованиями личными правами [Елистратов, 1917].

Проникновение в сферу государственного управления идеи общественного служения создает основу для закрепления обязательств в публично-правовой сфере, правомочий, основанных, например, на государственном страховании рабочих, страховании доходов и капиталов, на отношениях с правительственными или общественными кредитными учреждениями и т. п. А.И. Елистратов обращал внимание на то, что правоотношения, устанавливающиеся между государственными органами и гражданами, могут быть направлены на реализацию частного интереса, но по своему общественному назначению они в любом случае будут оставаться отношениями публичного характера [Елистратов, 1917].

А.И. Елистратов полагал, что государством должен быть определен и закреплен минимум прав, который должен быть обеспечен человеку общественным порядком. Основой концепции А.И. Елистратова являлась идея о праве на существование, или о праве на достойное человеческое существование. Потребностями существования А. Менгер называл те потребности, от удовлетворения которых зависит поддержание существования каждого отдельного лица и, соответственно, которые по своему практическому значению особенно важны. Эти потребности, полагал А. Менгер, отличаются более общим объективным характером и могут служить мерилом при распределении благ. Однако размер этих потребностей может различаться в зависимости от места и времени. Потребности являются основой права на существование: каждый член общества имеет право на вещи и услуги, необходимые для поддержания его существования, раныше, чем удовлетворены менее важные потребности других [Менгер, 1906, с. 8]. При этом право на существование, подчеркивал И. А. Покровский, не есть «конечный идеал», это только минимум того, что государство в настоящий момент должно обеспечить человеку [Покровский И.А., 1906, с. 35]

Понятие «право на существование» не тождественно понятию «право существования», смысловое наполнение которого связано с правом на жизнь как одним из прав гражданской свободы. При реализации права существования человек должен получить обязательное, гарантированное ему правопорядком, общественное обеспечение необходимых условий своего существования. Право существования должны обеспечивать необходимые условия здоровья, духовного развития и материального благосостояния индивида. Право на существование должно позволить обеспечить жизнь нетрудоспособных лиц - детей, больных, инвалидов и стариков. По отношению к безработным право существования могло бы выразиться в праве на труд [Елистратов, 1917, с. 125].

Важным достижением полицейско-правовой теории конца XIX - начала XX века являлась аргументация выводов о том, что обязательным элементом публично-правового статуса индивида являются его политические права - права на участие в государственной деятельности, прежде всего избирательное право. Политические права в гораздо большей степени, по сравнению с другими субъективными правами граждан, связаны с представлениями об общественном долге. Иногда они и прямо переходят в обязанность.

\section{О защите прав личности - субъекта публично-правовых отношений}

Рассматривая многообразие взаимоотношений между государством и личностью, полицеисты справедливо обращали внимание на то, что их упорядочению может способствовать опыт регулирования гражданско-правовых отношений, в частности, в сфере защиты нарушенных прав. С учетом эффективности защиты частных прав граждан посредством судебного разбирательства как средство защиты прав граждан в сфере публично- 
правовых отношений полицеистами рассматривалась административная юстиция - институт судебного обжалования актов управления.

Посредством хорошо организованной административной юстиции гражданин мог добиться отмены незаконного распоряжения должностного лица. При этом отменой незаконного распоряжения тот ущерб, который субъект понес от незаконной меры, примененной к нему в порядке административного принуждения, не устранялся. Поэтому гарантией нарушенных интересов выступала судебная ответственность должностных лиц.

Гражданско-правовая ответственность должностного лица предусматривает обязанность возместить из своих средств тот ущерб, который он причинил истцу своими неправомерными действиями или упущениями по службе [Елистратов, 1917, с. 287]. Возмещение вреда и убытков, причиненных должностными лицами, взыскивались в гражданском порядке путем предъявления иска к должностному лицу. В Российской империи решение вопросов подобного типа имело определенную специфику:

- устанавливалась краткая исковая давность, погашающая иски к должностным лицам (предусматривался срок на предъявление иска, равный трем месяцам со дня объявления просителю распоряжения, признаваемого им нарушающим его права, или равный шести месяцам со дня приведения такого распоряжения в действие, если оно исполнено без предварительного объявления);

- само решение дела происходило не в обыкновенном присутствии окружного суда и судебной палаты, а в особом их присутствии, в которое, помимо судей, входящих вицегубернаторов или губернаторов, входили и другие чины местных управлений (от администрации не зависело предание суду и связанное с ним допущение гражданского иска, но она могла проявить свое влияние на самом решении дела).

Данные обстоятельства существенно осложняли возмещение вреда и убытков, причиненных должностными лицами. Решению вопроса могла способствовать практика публично-правового вознаграждения, предполагающая, что убытки, причиненные частному лицу неправильными действиями или противозаконным бездействием должностного лица, должны возмещаться из тех же публичных финансов, с помощью которых функционирует и весь административный механизм [Елистратов, 1917, с. 289-290]. А.И. Елистратов подчеркивал, что при обосновании размера публично-правового вознаграждения представления об ответственности государства за чиновников следовало исключать. С установлением начала публично-правового вознаграждения ответственность должностных лиц не исчезает, но из ответственности перед частным лицом она может преобразовываться в ответственность перед казной. Возмещая ущерб гражданам, казна уже сама может взыскивать с должностного лица те убытки, причиной которого была его личная вина (право регресса).

Частное лицо может потерпеть ущерб не только от неправомерных, но и совершенно законных требований должностных лиц. В этом случае можно различать ущерб двоякого рода:

- лишения, которые должны претерпевать на равных основаниях все граждане, в виде уплаты налогов и исполнения повинностей;

- ущерб, который падает на определенное лицо (например, это потери для собственника, связанные с принудительным отчуждением его недвижимости, потери для предпринимателя в случае установления в данной отрасли хозяйства государственной монополии и т. п.).

\section{Заключение}

В конце XIX - начале XX в. отечественная полицейско-правовая мысль находилась в периоде расцвета. Полицейское право представляло собой самостоятельную национальную юридическую науку. В это время осуществлялась систематическая научная разработка проблем полицейской деятельности, была дана характеристика полиции как государ- 
ственного органа, принимавшего участие в обеспечении прав человека, проработаны вопросы о возможности ограничения прав человека при использовании мер принуждения администрацией и полицией. Этот период связан с деятельностью мыслителей, в числе которых И.Е. Андреевский, А.Я. Антонович, Н.Н. Белявский, Э.Н. Берендтс, Н.Х. Бунге, С.В. Ведров, В.М. Гессен, Н.А. Грифцов, В.Ф. Дерюжинский, А.И. Елистратов, В.В. Ивановский, В.Г. Иозефе, В.Н. Лешков, В.Ф. Левитский, А.Е. Назимов, Г.Ф. Симоненко, Я.С. Степанов, И.Т. Тарасов, А.А. Трифонов, А.И. Чупров, П.Н. Шеймин, М.М. Шпилевский, Н.Д. Яворский, И.И. Янжул. Именно этот период отмечен вниманием к анализу законодательства и попытками систематизации нормативных правовых актов в сфере организации и деятельности полиции, которые, в частности, предпринимали И.П. Высоцкий, М.И. Доброленский, Ф.Ф. Древинг, В.В. Лукин, В.И. Способин, Н.Н. Цылов.

Российская полицеистика демонстрировала стремление четко определить пределы ограничения законодательно закрепленных прав человека, границы полицейского вмешательства государства в частную и общественную жизнь.

Полицеисты сделали выводы о том, что полицейская деятельность является не только правом, но и обязанностью государства; при этом помощь отдельному лицу при достаточности его собственных сил оказываться не должна, а если таковых не хватает, управленческие и правоохранительные функции осуществляют институты гражданского общества, и только при недостаточности усилий последних должна осуществляться полицейская деятельность органов государства. Также в исследованиях полицеистов

- аргументирован вывод о необходимости законодательного закрепления прав и свобод человека;

- определены пределы вмешательства государства в сферу частной жизни и основания ограничений прав человека;

- сделан вывод о том, что средством защиты и восстановления нарушенных администрацией прав призвана стать административная юстиция;

- оформлена идея о необходимости правового ограничения государственной власти и установления границ принудительной деятельности администрации;

- обоснован вывод о роли и месте административной юстиции в государственноправовой системе правового государства, о значении административной юстиции для обеспечения прав и свобод человека и гражданина.

Впервые в отечественной юридической науке тщательному изучению были подвергнуты административно-правовые отношения, субъектами которых выступают должностные лица и граждане. Полицеисты выявили тенденцию сближения статусов должностного лица и гражданина в правовом государстве.

Отсутствие формально организованной целостной системы административной юстиции в Российской империи полицеисты считали серьезным недостатком государственноправовой системы России, а отсутствие института судебного обжалования актов управления в России - серьезным недостатком системы охраны и защиты прав и свобод личности.

Осмысление важных проблем, касающихся законодательного закрепления прав и свобод личности и их реализации, осуществленное полицейско-правовой теорией в конце XIX - начале XX в., до настоящего времени сохраняет потенциал детерминанты эффективного регулирования общественных отношений и может быть использовано для совершенствования механизма защиты прав личности - субъекта публично-правовых отношений в современной России.

\section{Список источников}

1. Андреевский И.Е. 1874-1876. Полицейское право. Т. 1-2. СПб., Тип. В.В. Пратц.

2. Берендтс Э.Н. 1898. Опыт системы административного права. Т. І. Вып. І. Обзор истории административного права и истории его литературы. Ярославль, Типо-лит. Э.Г. Фальк, 263 c. 
3. Вольф Х., фон. 1765. Разумные мысли о силах человеческого разума и их исправном употреблении в познании правды. Любителям оной изданы, чрез г. Вольффа королевскаго шведскаго высоко-княжескаго гессенскаго придворнаго советника, перваго профессора математики и филозофии в Марбурге, профессора гонорарио в Санктпетербурге, Королевскаго Великобританскаго, так же Королевскаго Прусскаго собрания наук члена; Переведены в 1753 году Б[егичевым] М[атвеем]. СПб., Тип. Артиллерийского и Инженерного Шляхетного Кадетского Корпуса, 304 c.

4. Гессен В.М. 1903. Административное право. Попул. лекции для самообразования. СПб., Паровая скоропеч. Г. Пожарова, 240 с.

5. Гессен В.М. 1902. Из лекций по полицейскому праву. СПб., Типо-лит. М. Гинсбурга, $354 \mathrm{c}$. $195 \mathrm{c}$.

6. Гессен В.М. 1908а. Лекции по полицейскому праву. Вып. 1. СПб., Типография «Север»,

7. Гессен В.М. 1908б. Русское государственное право. Лекции. СПб., Студ. касса взаимопомощи студентов С.-Петерб. политехн. ин-та, 335 с.

8. Гессен В.М. 1918. Основы конституционного права. Петроград, Юрид. кн. скл. «Право», $445 \mathrm{c}$.

9. Дерюжинский В.Ф. 1917. Полицейское право. Пособие для студентов. Петроград, Сенатск. тип., $510 \mathrm{c}$. $235 \mathrm{c}$.

10. Елистратов А.И. 1910. Административное право. Лекции. М., Тип. т-ва И.Д. Сытина,

11. Елистратов А.И. 1912. Государственное право. Пособие к лекциям. М., Печатня А. Снегиревой, 360 c.

12. Елистратов А.И. 1914. Основные начала административного права. М., Изд-во Г.А. Лемана, $332 \mathrm{c.}$

13. Елистратов А.И. 1915. Очерк государственного права (Конституционное право). М., Тип. «Мысль», 166 с.

14. Елистратов А.И. 1910-1911. Учебник русского административного права. Пособие к лекциям. Вып. 1-2. М., О-во взаимопомощи студентов-юристов Моск. ун-та.

15. Елистратов А.И. 1911. Учебник русского административного права. Пособие к лекциям. Вып. 1. М., Т-во скоропеч. А. А. Левенсон, 96 с.

16. Елистратов А.И. 1917. Основные начала административного права. М., Г.А. Леман и С.И. Сахаров, 294 с.

17. Ивановский В.В. 1908. Учебник административного права (Полицейское право. Право внутреннего управления). Казань, Типо-лит. Имп. ун-та, 539 с.

18. Кистяковский Б.А. 1916. Социальные науки и право: Очерки по методологии социальных наук и общей теории права. М., М. и С. Сабашниковы, 708 с.

19. Менгер А. 1906. Право на полный продукт труда. СПб., О.Н. Попова, 138 с.

20. Покровский И.А. 1906. Право на существование. Свобода и культура, 4: 32-38.

21. Тарасов И.Т. 1888. Краткий очерк науки административного права. Конспект лекций в 2 т. Ярославль, Типо-лит. Г. В. Фальк.

22. Тарасов И.Т. 1908-1915. Лекции по полицейскому (административному) праву. Т. 1-3. М., Тип. Моск. ун-та.

23. Тарасов И.Т. 1891-1896. Учебник науки полицейского права. Вып. 1-4. М.: Т-во «Печатня С. П. Яковлева».

24. Delamare N. 1719-1738. Traité de la police où l'on trouvera l'histoire de son établissement, les fonctions et les prérogatives de ses magistrats, toutes les lois et tous les règlements qui la concernent: On y a joint une description historique et topographique de Paris, \& huit Plans gravés, qui représentent son ancien Etat, \& ses divers accroissements, avec un recueil de tous les statuts et règlements des six corps des marchands, \& de toutes les Communautés des Arts \& Métiers. Par M. Delamare, ConseillerCommißaire du Roy au Châtelet de Paris. 2-eme éd. Vol. 1-4. Paris: Chez Michel Brunet et chez J.-F. Hérissant.

25. Justi J. H. G., von. 1759. Grundsätze der Polizeiwissenschaft in einen vernünftigen, auf den Endzweck der Polizei gegründeten, Zusammenhang und zum Gebrauch Academischer Vorlesungen abgefasset. Göttingen, Vandenhoeck, 348 p. 
26. Sonnenfels J. F., von. 1765-1769. Grundsätze der Polizei, Handlung und FinanzWissenschaft. Bd. 1-3. Wien: von Trattner.

27. Wolff Chr., von. 1720-1724. Vernünftige Gedanken von Gott, der Welt und der Seele des Menschen, auch allen Dingen überhaupt. T. 1-2. Frankfurt am Main.

\section{Список литературы}

1. Дергилева С.Ю. 2015. Российская полицеистика в лицах: Аркадий Иванович Елистратов. Genesis: исторические исследования, 6: 844-859.

2. Дергилева С.Ю. 2019. Диссертация С.А. Никифоровой - вклад в изучение государственно-правовых учений Э.Н. Берендтса. Вестник Санкт-Петербургского университета МВД России, 4 (84): 226-230.

3. Егоров Н.Ю. 2020. Административная юстиция как средство обеспечения прав и свобод личности (опыт анализа теоретического наследия И. Т. Тарасова). Вестник СанктПетербургского университета МВД России, 1 (85): 10-17.

4. Козинникова Е.Н. 2020. Цензура как предмет полицейско-правовой теории в Российской империи конца XIX - начала XX века. Вестник Санкт-Петербургского университета МВД России, 1 (85): 18-23.

5. Козинникова Е.Н. 2020. Полицейский надзор как мера обеспечения чрезвычайного правового режима исключительного положения в оценке российских полицеистов конца XIX начала XX века. Вестник Уральского юридического института МВД России, 2 (86): 106-112.

6. Морозова Е.Н., Нижник Н.С. 2020. Реформирование российской полиции: плюрализм подходов к осуществлению в середине XIX века. Вестник Санкт-Петербургского университета МВД России, 2 (86): 30-39.

7. Нижник Н.С., Дергилева С.Ю. 2017. Государство и право в теоретико-правовых воззрениях А.И. Елистратова. М., Издательство «Юрлитинформ», 376 с.

8. Нижник Н.С., Дергилева С.Ю., Геворкян Д.С. 2014. Философия эвдемонизма как концептуальная основа теории и практики полицейского государства. Вестник СанктПетербургского университета МВД России, 3: 236-242.

9. Нижник Н.С., Дергилева С.Ю. 2014. Государство и право в теоретическом наследии А.И. Елистратова. Вестник Санкт-Петербургского университета МВД России, 2 (62): 66-73.

10. Нижник Н.С. 2019. Полицейско-правовая теория - предмет исследования современных учёных. Вестник Санкт-Петербургского университета МВД России, 4 (84): 231-240.

11. Нижник Н.С. 2018. Полицейское государство - социоюридический феномен: характеристика сущностных черт в отечественной полицейско-правовой теории. Вестник Нижегородского университета им. Н.И. Лобачевского, 6: 123-130.

12. Нижник Н.С. 2016. Полицейское государство - государство «всеобщего благоденствия и всеобщего счастья». Genesis: исторические исследования, 6: 183-194.

13. Нижник Н.С., Никифорова С.А. 2019. Государство и право в теоретико-правовых воззрениях Э. Н. Берендтса. М., Юрлитинформ, 232 с.

14. Нижник Н.С., Никифорова С.А. 2019. Теоретическое наследие Э. Н. Берендтса - вклад в развитие российской полицейско-правовой теории. Вестник Санкт-Петербургского университета МВД России, 2(82): 53-70.

15. Пирожок С.С. 2020. Теоретико-методологические детерминанты концепции социального государства Роберта фон Моля. Вестник Санкт-Петербургского университета МВД России, 1 (85): 37-45.

16. Тарасов Н.К. 2019. Российская полицеистика конца XIX - начала XX века об основаниях и пределах применения мер государственного принуждения. Вестник СанктПетербургского университета МВД России, 4 (84): 51-60.

17. Туманова А.С. 2019. Завершено ещё одно исследование теоретического наследия российских полицеистов. Вестник Санкт-Петербургского университета МВД России, 4 (84): 221225.

18. Nizhnik N. 2019. 300 years in the service to the native land: specifics of the regional development of the police bodies in the Russian empire (on the materials of the jubilee international scientific conference held at St Petersburg university of the Ministry of internal affairs). Historia provinciae - the journal of regional history, v. 3, 1: 505-522. 


\section{References}

1. Dergileva S.Yu. 2015. Rossijskaya policeistika v licah: Arkadij Ivanovich Elistratov [Russian politistika in persons: Arkadii I. Elistratov]. Genesis: istoricheskie issledovaniya [Genesis: historical research], 6: 844-859. (in Russian).

2. Dergileva S.Yu. 2019. Dissertaciya S.A. Nikiforovoj - vklad v izuchenie gosudarstvennopravovyh uchenij E.N. Berendtsa [Dissertation of S.A. Nikiforova-contribution to the study of state-legal teachings of E.N. Behrendts]. Vestnik Sankt-Peterburgskogo universiteta MVD Rossii [Bulletin of the Saint Petersburg University of the Ministry of internal Affairs of Russia], 4 (84): 226-230. (in Russian).

3. Egorov N. Yu. 2020. Administrativnaya yusticiya kak sredstvo obespecheniya prav i svobod lichnosti (opyt analiza teoreticheskogo naslediya I.T. Tarasova) [Administrative justice as a means of ensuring individual rights and freedoms (experience in analyzing the theoretical heritage of I.T. Tarasov)]. Vestnik Sankt-Peterburgskogo universiteta MVD Rossii [Bulletin of the Saint Petersburg University of the Ministry of internal Affairs of Russia], 1 (85): 10-17. (in Russian).

4. Kozinnikova E.N. 2020a. Cenzura kak predmet policejsko-pravovoj teorii v Rossijskoj imperii konca XIX - nachala XX veka [Censorship as a subject of police-legal theory in the Russian Empire of the late XIX-early XX century]. Vestnik Sankt-Peterburgskogo uni-versiteta MVD Rossii [Bulletin of the Saint Petersburg University of the Ministry of internal Affairs of Russia], 1 (85): 18-23. (in Russian).

5. Kozinnikova E.N. 2020б. Policejskij nadzor kak mera obespecheniya chrezvychaj-nogo pravovogo rezhima isklyuchitel'nogo polozheniya $\mathrm{v}$ ocenke rossijskih policeistov konca XIX - nachala $\mathrm{HKH}$ veka [Police supervision as a measure to ensure an emergency legal regime of an exceptional position in the assessment of Russian police officers of the late XIX-early XX century]. Vestnik Ural'skogo yuridicheskogo instituta MVD Rossii [Bulletin of the Ural law Institute of the Ministry of internal Affairs of Russia], 2 (86): 106-112. (in Russian).

6. Morozova E.N., Nizhnik N.S. 2020. Reformirovanie rossijskoj policii: plyuralizm podhodov $\mathrm{k}$ osushchestvleniyu $\mathrm{v}$ seredine XIX veka [Reforming the Russian police: pluralism of approaches to implementation in the middle of the XIX century]. Vestnik Sankt-Peterburgskogo universiteta MVD Rossii [Bulletin of the Saint Petersburg University of the Ministry of internal Affairs of Russia], 2 (86): 30-39. (in Russian).

7. Nizhnik N.S., Dergileva S.Yu. 2017. Gosudarstvo i pravo v teoretiko-pravovyh vozzreniyah A.I. Elistratova [State and law in the theoretical and legal views of A.I. Elistratov]. M.: Izdatel'stvo «YUrlitinform»: 376. (in Russian).

8. Nizhnik N.S., Dergileva S.Yu., Gevorkyan D.S. 2014. Filosofiya evdemonizma kak konceptual'naya osnova teorii i praktiki policejskogo gosudarstva [The philosophy of eudaimonism as a conceptual basis for the theory and practice of the police state]. Vestnik Sankt-Peterburgskogo universiteta MVD Rossii [Bulletin of the Saint Petersburg University of the Ministry of internal Affairs of Russia], 3: 236-242. (in Russian).

9. Nizhnik N.S., Dergileva S.Yu. 2014. Gosudarstvo i pravo v teoreticheskom nasledii A.I. Elistratova [State and law in the theoretical heritage of A.I. Elistratov]. Vestnik SanktPeterburgskogo universiteta MVD Rossii [Bulletin of the Saint Petersburg University of the Ministry of internal Affairs of Russia], 2 (62): 66-73. (in Russian).

10. Nizhnik N.S. 2019. Policejsko-pravovaya teoriya - predmet issledovaniya sovremennyh uchyonyh [Police and legal theory is the subject of research by modern scientists]. Vestnik SanktPeterburgskogo universiteta MVD Rossii [Bulletin of the Saint Petersburg University of the Ministry of internal Affairs of Russia], 4 (84): 231-240. (in Russian).

11. Nizhnik N.S. 2018. Policejskoe gosudarstvo - socioyuridicheskij fenomen: harakteristika sushchnostnyh chert $\mathrm{v}$ otechestvennoj policejsko-pravovoj teorii [The police state is a socio-legal phenomenon: characteristics of essential features in the national police and legal theory]. Vestnik Nizhegorodskogo universiteta im. N.I. Lobachevskogo [Bulletin of the Lobachevsky University of Nizhny Novgorod], 6: 123-130. (in Russian).

12. Nizhnik N.S. 2016. Policejskoe gosudarstvo - gosudarstvo «vseobshchego blago-denstviya i vseobshchego schast'ya» [The police state is a state of «universal welfare and universal happiness»]. Genesis: istoricheskie issledovaniya [Genesis: historical research], 6: 183-194. (in Russian).

13. Nizhnik N.S., Nikiforova S.A. 2019. Gosudarstvo i pravo v teoretiko-pravovyh vozzreniyah 
E.N. Berendtsa [State and law in the theoretical and legal views of E.N. Berendts]. M.: YUrlitinform: 232. (in Russian).

14. Nizhnik N.S., Nikiforova S.A. 2019. Teoreticheskoe nasledie E.N. Berendtsa - vklad v razvitie rossijskoj policejsko-pravovoj teorii [Behrendts ' theoretical legacy is a contribution to the development of Russian police and legal theory]. Vestnik Sankt-Peterburgskogo universiteta MVD Rossii [Bulletin of the Saint Petersburg University of the Ministry of internal Affairs of Russia], 2(82): 53-70. (in Russian).

15. Pirozhok S.S. 2020. Teoretiko-metodologicheskie determinanty koncepcii social'nogo gosudarstva Roberta fon Molya [Theoretical and methodological determinants of the concept of the social state by Robert von Mol]. Vestnik Sankt-Peterburgskogo universiteta MVD Rossii [Bulletin of the Saint Petersburg University of the Ministry of internal Affairs of Russia], 1 (85): 37-45.

16. Tarasov N.K. 2019. Rossijskaya policeistika konca XIX - nachala XX veka ob osnovaniyah i predelah primeneniya mer gosudarstvennogo prinuzhdeniya [Russian politseistics of the late XIX-early XX century on the grounds and limits of the use of state coercion measures]. Vestnik SanktPeterburgskogo universiteta MVD Rossii [Bulletin of the Saint Petersburg University of the Ministry of internal Affairs of Russia], 4 (84): 51-60. (in Russian).

17. Tumanova A.S. 2019. Zaversheno eshchyo odno issledovanie teoreticheskogo naslediya rossijskih policeistov [Another study of the theoretical heritage of Russian police officers has been completed]. Vestnik Sankt-Peterburgskogo universiteta MVD Rossii [Bulletin of the Saint Petersburg University of the Ministry of internal Affairs of Russia], 4 (84): 221-225. (in Russian).

18. Nizhnik N. 2019. 300 years in the service to the native land: specifics of the regional development of the police bodies in the Russian empire (on the materials of the jubilee international scientific conference held at St Petersburg university of the Ministry of internal affairs). Historia provinciae - the journal of regional history, v. 3, 1: 505-522.

\section{ИНФОРМАЦИЯ ОБ АВТОРАХ}

Нижник Надежда Степановна, доктор юридических наук, кандидат исторических наук, профессор, заслуженный работник высшей школы Российской Федерации, начальник кафедры теории государства и права СанктПетербургского университета МВД России, г. Санкт-Петербург, Россия

Дергилева Светлана Юрьевна, кандидат юридических наук, начальник адъюнктуры Белгородского юридического института МВД России имени И.Д. Путилина, г. Белгород, Россия

\section{INFORMATION ABOUT THE AUTHORS}

Nadezhna S. Nizhnik, doctor of law, candidate of historical sciences, professor, honored worker of higher education of the Russian Federation, head of the Department of theory of state and law, SaintPetersburg University of the Ministry of Internal Affairs of Russia, Saint-Petersburg, Russia

Svetlana Y. Dergileva, candidate of juridical sciences head of graduate school Department, Belgorod Institute of the Ministry of Internal Affairs of Russia named after I. D. Putilin, Belgorod, Russia 